\title{
Response from Dilip Dan to Commentary from Inge on Case Report OBSU-D-09-00159
}

\author{
Dilip Dan • Dave Harmanan • Shiva Seetahal • \\ Vijay Naraynsingh $\cdot$ Suruipal Teelucksingh
}

Received: 9 October 2009 / Accepted: 9 October 2009 /Published online: 21 October 2009

(C) Springer Science + Business Media, LLC 2009

We would like to thank Professor Inge for his commentary and agree with most of the comments. It has been said that the first step of a journey is usually the most important and often the most difficult. This case was the first in our collective experience and provided an extraordinarily difficult therapeutic challenge. The risk/benefit ratio of bariatric surgery is well established in the morbidly obese adult and is under current investigation in teenagers. The decision to undertake a sleeve gastrectomy in one so young and with such debility as in the current case was the Aristotelian mean of cost, benefit, availability, feasibility, and accessibility of therapeutic options. We agree that our work with this child has just begun!

It is clear even from the commentary that little is known about the management of such a case and the long-term sequelae of medical or surgical options. The only real option provided was the use of octreotide. The long-term effects of this may also be harmful and cost prohibitive in our setting. There is tremendous investigational work with ghrelin and other hormones in the understanding of the physiology of weight gain and loss, and much work is also being done on the whole issue of the true mechanism of bariatric surgery. However, this is investigational and would be of little help to this patient in our setting today.

Suffice it to say that we exercised what appeared to be the best option in our circumstances fully cognizant of our responsibility to carefully follow-up the patient and manage the metabolic consequences of this intervention. It has been over 2 years since her surgery and she continues to do very well. We will continue our follow-up of the patient and would be pleased to inform you through this journal of her progress in 5 years.
D. Dan $(\bowtie)$

Department of Surgery, UWI, San Fernando General Hospital,

San Fernando, Republic of Trinidad and Tobago

e-mail: dilipdan5@gmail.com

S. Seetahal

Department of Surgery, San Fernando General Hospital,

683 Orbit Street, Lange Park, Chaguanas,

San Fernando, Republic of Trinidad and Tobago

e-mail: shiva_seetahal@yahoo.com

D. Harmanan

Department of Surgery, San Fernando General Hospital,

San Fernando, Republic of Trinidad and Tobago

V. Naraynsingh $\cdot$ S. Teelucksingh

University of the West Indies, Trinidad Campus,

St Augustine, Republic of Trinidad and Tobago 